\title{
Gender Differences in Elementary School Students' Game Design Preferences
}

\author{
Hui-Mei Justina Hsu, Member, IACSIT
}

\begin{abstract}
A visual programming environment, Scratch, is widely used by young students, and is reported to improve the participation of females in the field of computer science. The purpose of this study is to investigate gender differences among elementary school students' game design preferences. The participants in this study are eight 2nd graders, four boys and four girls, with few programming experiences. The experimental sessions are conducted for 8 weeks with one instructor facilitating students' game design. Each session lasts for two hours. As they are limited in their knowledge of programming, the participants are given model examples to work with. Gender differences in game design preferences are measured by examining student works. The results indicate that (1) girls are more interested in drawing, while boys are more interested in designing game interactions, (2) when it comes to character selection, girls are fond of drawing realistic characters while boys like to use Scratch built-in characters, (3) both boys and girls are interested in taking the challenges of the model examples, and (4) girls are more motivated to incorporate multimedia into their projects.
\end{abstract}

Index Terms - Gender differences, kid's programming, game design, scratch, educational games.

\section{INTRODUCTION}

There is a considerable concern about the gender imbalance in the field of science and technology. According to the Research, Development and Evaluation Commission in Taiwan, gender differences in computer usage are gradually being reduced [1]. As far as job orientation is concerned, however, the gender imbalance in the high-tech industry is rather apparent [2]. In BenQ (a software company), 15-17\% of the engineers are women, while in Powerchip Semiconductor (a hardware company) female engineers make up 3\%-4\% of the total engineer population. Despite the fact that gender digital divide is gradually shrinking, the gender imbalance in the high-tech industry is rather apparent.

Gender differences in computer use have been well documented in the literature. In terms of gender differences in students' online activities, female students tend to use the Internet to broaden their social network, while male students use it to play games [3], [4]. The findings are similar to the researcher's campus observations in Taiwan. Female students enjoy using computers to compose articles in their personal blogs or to use Facebook to connect with their friends. On the other hand, the male students are fond of

Manuscript received November 15, 2012; revised January 15, 2013. This work was supported by by the National Science Council, Taiwan, ROC, under Project NSC 100-2511-S-431-003.

Hui-Mei Justina Hsu is with the Applified Informatics Department, Fo Guang University, Yilan, 26247 Taiwan (e-mail: justina.hsu@gmail.com). playing online shooting games such as Counter Strike Online and Special Force Online.

Gender differences in students' computer interests and performances are an important issue related to equal participation in the hi-tech industry. There are several reasons why girls are less interested in using computers and less proficient in computer skills than boys. Among them, access is believed to play an important role in students' computer literacy. When male and female students are given equal access to computers, their programming performances are the same [5]. As they grow older, girls do not have extensive out-of-school computer experiences as compared to boys [6]. When they have computer classes at school, therefore, girls are less capable in computer skills and experience more pressure than boys [7]. In addition, the hi-tech industry requires not only computer literacy but also high-level technological fluency, which emphasizes the ability to use technology to process information, communicate and solve problems. The fact that high-level technological fluency is not stressed at school results in female students not having the chance to access real computer science [8]. Consequently, many studies (e.g. [6], [9]-[11]) implement game design and multimedia courses in elementary and high schools to investigate gender differences in designing strategies, styles and solving encountered problems.

\section{PURPOSE OF STUdY}

This study investigates a Scratch class implemented as an extracurricular activity in an elementary school setting. The purpose of this study is to explore gender differences regarding preferences in game design by comparing students' final products.

\section{A. Gendered Computer Practices}

Gender differences are found in studies investigating computer practices and are summarized as follows:

\section{1) Role of the computer}

Male students tend to use computers to play games and to program, and regard computers as a recreational toy. On the other hand, female students consider computers as a tool for task completion [12].

\section{2) Types of online activities}

Boys tend to play online games, especially violent games, while girls use the computer to communicate and broaden their personal relationships [3].

\section{3) Types of games}

Boys like adventure games emphasizing targets and speed, 
while girls prefer games with educational meanings [9].

\section{B. Scratch and Gender}

Scratch (http://scratch.mit.edu/) is an educational programming language developed by the Lifelong and Kindergarten group at the MIT Media Lab. It is a visual programming environment designed for students aged from 8 to 16 as shown in Fig. 1. Scratch enables female participation in the field of computer science and is labeled as a "promising practice" for increasing gender diversity in IT by The National Center for Women \& Information Technology [13]. Furthermore, Scratch is employed as the major content in the introductory Computer Science course at Harvard, which results in a marked increase in the retention of female students [14]. In addition, Scratch seems to be appealing to girls [15]. Compared to the previous LEGO robotics programming activities with only $30 \%$ female students, the participation in Scratch programming activities is more balanced in gender [15]. The above studies illustrate that Scratch can indeed be successful in promoting female students' interest in programming.

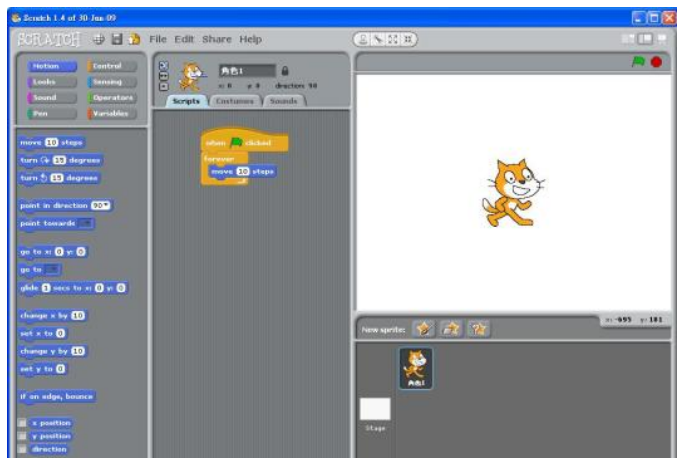

Fig. 1. Scratch interface.

\section{Gender Prefernces in Game Design}

Since the 1990s, Seymour Papert and Yasmin Kafai have conducted various research studies on children's game design in the elementary schools in Boston. They adopt qualitative research methods, such as observation, interview and work analysis to investigate what students do and learn during game design activities. Mary research papers such as [6], [9], [10] are generated to address the issue of gender preferences in game design. The following is a brief summary of these studies.

1) Game design style

a) Genre

The games designed by children can be divided into three types: adventure, sports/skills, and teaching [10]. Kafai finds that boys prefer to design adventure games and are reluctant to design teaching games. Though they create adventure games, girls make quite a few instructional games. In one of the game design projects, girls create more teaching games than adventure games.

b) Game world

Games need to be situated in game worlds. Gender differences are apparent in selecting game worlds. Boys prefer fantasy worlds, while girls prefer realistic worlds.

c) Player character

Girls tend not to give players specific names but use generic "you" to address them, while boys tend to give players specific names.

\section{d) Feedback}

Male students tend to use negative reinforcements. When players answer a wrong answer, their games tend to give violent feedback.

\section{2) Game design strategy}

\section{a) Participation in activities}

Activities are classified into three types, namely: enriching activities, constancy activities and traditional activities [6]. The result of their study indicates that at the initial stage, girls are involved in traditional activites such as book corner research and drawing screens on paper, while boys are involved in enriching activities such as leading group demos and teaching others to program. But there is not much difference at a later stage with both are deeply engaged in enriching activities and less engaged in traditional activities.

\section{b) Need for social space}

Girls are not involved in programming at the early stage of game design [6]. They focus on researching or do their graphics and let the boys in their teams use the computer. Second, girls seem to favor immediate discussion when problems occur, while male students seem to be more concerned about the completion of the project. When conflicts occur, boys and girls have different needs for social space. In order to coordinate the needs of both sexes, the researchers arrange a meeting time for the children to discuss the group problems.

\section{c) Physical space}

When girls design games, they like to work as a group and discuss with their group members. In the design process, girls are often not in their seats. In contrast, boys have a more independent working style. They stay in their seats most of the time. To be able to meet the girls' game design style, the researchers add computers so that female students can use the nearby computer to discuss with their peers.

\section{METHOD}

The study is situated in a Scratch game design class of 12 first, second, third and four graders (see Table I). In order to control gender and age of the participants, only the eight 2 nd graders, with four boys and four girls, are recruited to participate in this study. Another reason for selecting the 2nd graders is that their relative inexperience with programming can make gender differences apparent.

\begin{tabular}{|c|c|c|c|c|}
\hline Grade & $1^{\mathrm{st}}$ & $2^{2^{\text {nd }}}$ & $3^{\mathrm{rd}}$ & $4^{\text {th }}$ \\
\hline No. of Students & 1 & 8 & 2 & 1 \\
\hline
\end{tabular}

The Scratch game design class is implemented as an extracurricular activity occurring from 1:30 to 3:30 every Wednesday afternoon. Due to the fact that the research site adopts a quarter system, 10 design sessions are planned in Spring 2012. The session during Week 5 and Week 8 are cancelled because of national holidays and class suspension. 
Each session lasts for two hours.

The class takes place in a computer classroom. Every student has a computer for his/her personal use. The students are seated along the wall with the teacher's computer located in the front center as shown in Fig. 2. The students can pick their own seats, but girls always sit with girls and boys sit with boys. One screen broadcasting software program is utilized for the teacher and students to view one another's screens.

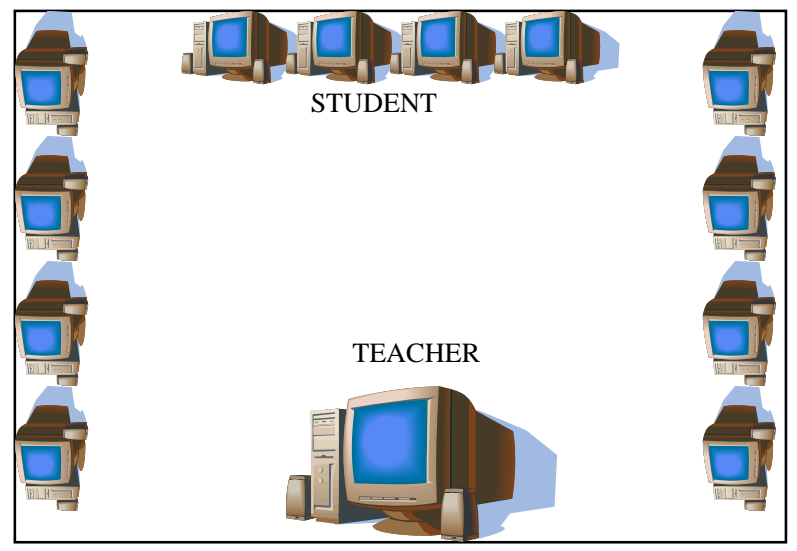

Fig. 2. Classroom configuration.

Modeling examples is adopted as the major method of instruction, because the participants are limited in their knowledge of programming. Every experimental session is composed of 1-5 model examples. The session is divided into two stages. At the first stage, the instructor begins each model example with questions. Questions are asked, such as "What key will initiate the program?", "What will speed up the bullet?", "How can we boost up the score?" etc. Guided by the instructor's questions, students are motivated to read the codes and change the parameters. At the second stage, the students are given some free time to tweak the given examples. They are free to talk with the other students or share their products. Most of the students tend to ask the instructor for help when they encounter difficulties. In order to demonstrate what students may do, Fig. 3 and Fig. 4 are provided. Fig. 3 is a maze game provided by the instructor for students to use as a model. Fig. 4 is a modified version by one student with several moving crosses to increase the difficulty of the game.

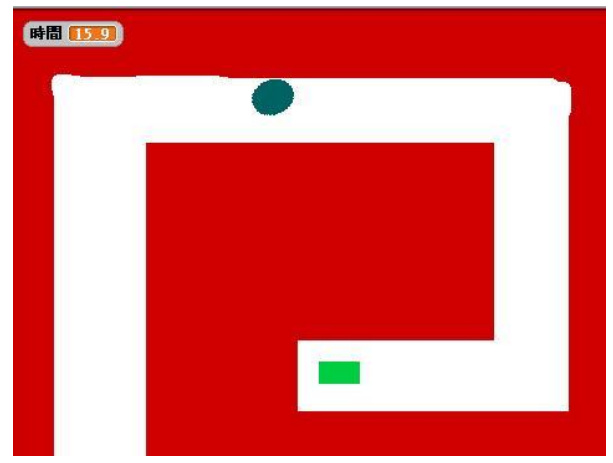

Fig. 3. Model Example.

Gender differences in students' game design preferences are measured by student works. Student works have been systematically collected since Week 3 . In total, there are 15 model examples collected as shown in Table II. The student works are analyzed based upon their focus of game design, characters, interaction, and the use of multimedia.

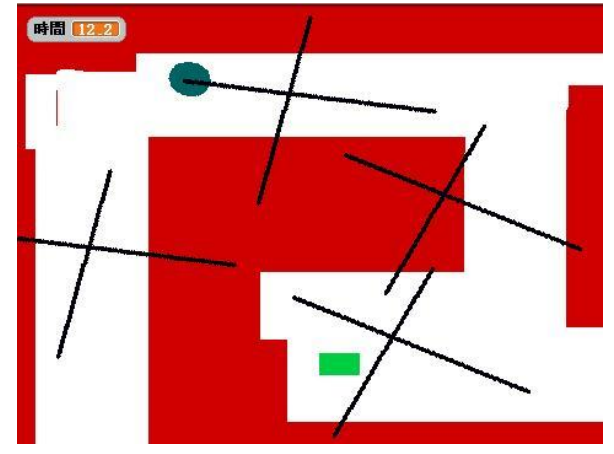

Fig. 4. Student work.

TABLE II: NUMBER OF MODEL EXAMPLES COLLECTED

\begin{tabular}{|c|c|c|c|c|c|c|}
\hline \hline Week & 3 & 4 & 6 & 7 & 9 & $\begin{array}{l}1 \\
0\end{array}$ \\
\hline No. of Model Examples Collected & 1 & 3 & 1 & 4 & 3 & 3 \\
\hline \hline
\end{tabular}

\section{RESUlts}

In the presentation of results, gender differences are discussed according to the focus of game design, characters, interaction, and the use of multimedia.

\section{A. Focus of Game Design}

When students are given free time, girls are more interested in drawing their own characters and backgrounds. For example, Fig. 5 is a Scratch project created at Week 4 by a girl with her drawing of a cat but without any codes. On the other hand, boys are more interested in designing interactions. Fig. 6 is a Scratch project created at Week 4 by a boy with a character drawing on the screen. Though he made the character by himself, he put a great deal of effort into writing the codes as shown in Fig. 7 to make the game interactive.

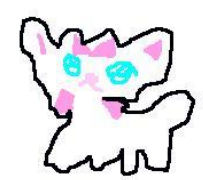

Fig. 5. Cat project by a girl with no codes.

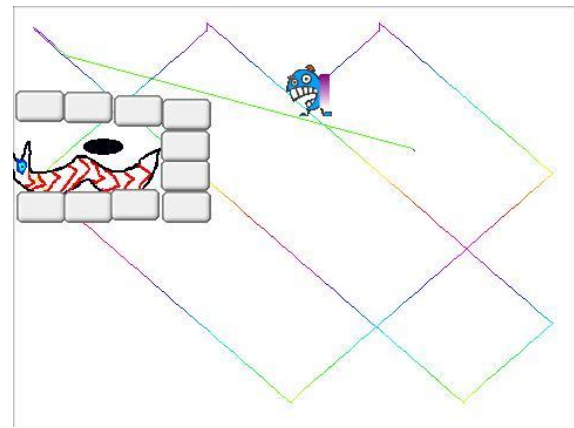

Fig. 6. Drawing project by a boy. 


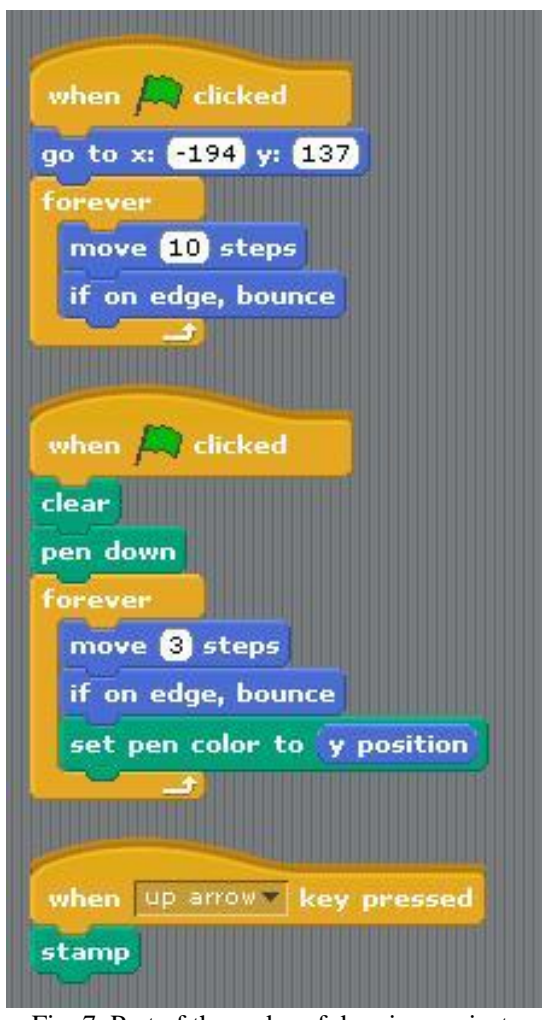

Fig. 7. Part of the codes of drawing project.

\section{B. Character}

Girls seem to be more willing to draw their own characters. According to the Scratch projects created by the students at Week 3, one out of the four girls used the built-in characters provided by the Scratch program, while three out of the four boys use the built-in characters. When creating characters, girls tend to create realistic creatures, while boys tend to create fantasy creatures as shown in Fig. 8 and Fig. 9.
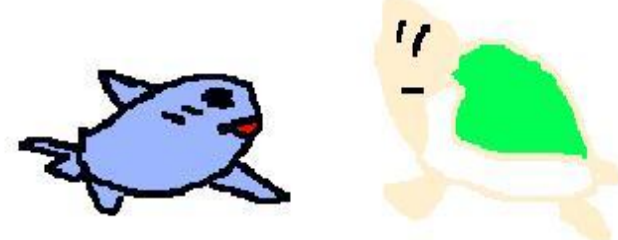

Fig. 8. Characters created by female students.

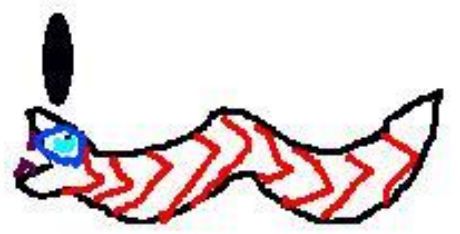

Fig. 9. Character created by a male student.

\section{Interaction}

Both boys and girls are interested in playing with the model games and in looking for ways to increase the possibilities of winning. When one student creates a new winning strategy, the other students will try to model his/her strategies. At Week 4, the instructor gives students a ping pong game. One of the girls discovers a winning strategy by placing the bar right against the ceiling as shown in Fig. 10.
The rest of the girls immediately modeled her winning strategy. It seems that both genders are equally interested in the challenges provided by the model examples.

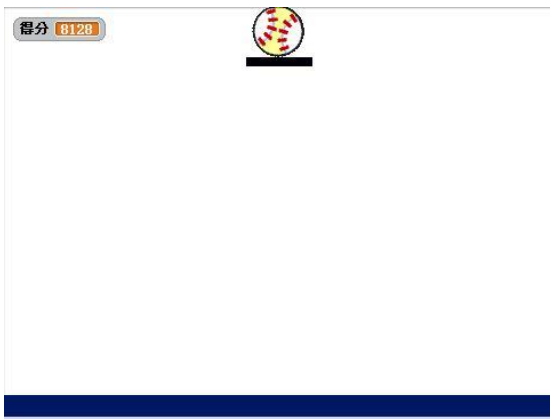

Fig. 10. Ping pong game with a winning strategy.

\section{Use of Multimedia}

Girls are more interested in the manipulation of multimedia than boys. At Week 9, the instructor starts to incorporate multimedia into game design. At first, both girls and boys are interested in the appearance of headsets and enjoy recording their own voices. In the end, girls have 100\% completion rate of the project, while boys seem to be rather disinterested in finishing the project. Boys seem to have more fun creating their own dialogue and seem to be shy about listening to their own voices. Another reason may have to do with the genre of the game, which may happen to be a type in which boys are not interested. The multimedia project is an animation game with a snail telling a snake a joke as shown in Fig. 11.

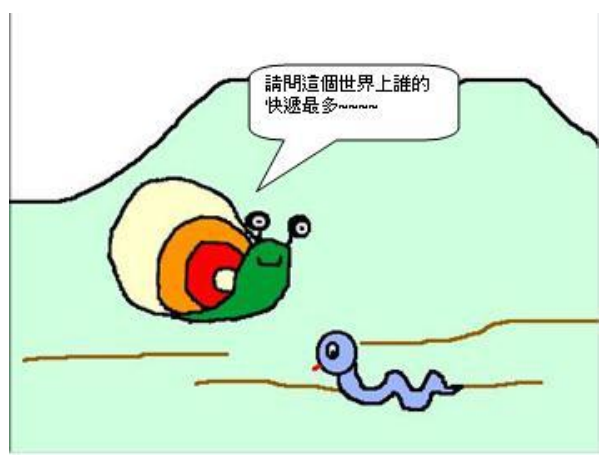

Fig. 11. Animation game with student recording.

\section{DISCUSSION AND IMPLICATIONS}

In the discussion of results, several issues which arise from the findings are addressed. First, there are apparent gender differences in elementary school students' game design preferences. The findings are similar to those reported in the literature. Girls tend to be more interested in multimedia activities such as drawing and recording, while boys tend to be more interested in designing interactions of games. Such gender orientations may result in the phenomenon that boys tend to spend more time in reading as well as writing codes and thus these behaviors may prepare them to be better software engineers. Second, girls are more oriented to the real world than boys. Similar to Kafai (2000), girls in the current study enjoy drawing realistic characters while boys are engaged in fantasy characters. As the model examples use scores as the major feedback, both boys and girls enjoy the 
interactions of games. Future studies may test gender differences using different feedback patterns. For example, fantasy worlds, characters, and negative feedback can be included to test gender preferences. Third, the participants in the current study are very young, but gender preferences seem to be rather significant. Future studies can be conducted to trace out-of-school computer experiences in order to identify the possible explanation for gender differences. Fourth, Scratch seems to be appealing to girls, but they are attracted to it due to the manipulation of multimedia. It is a good research topic to see how the interest in multimedia can help girls move into the world of programming.

\section{REFERENCES}

[1] Research, Development and Evaluation Commission, Executive Yuan, "2010 digital divide survey annual report," Taipei: Research, Development and Evaluation Commission, Executive Yuan, 2010.

[2] X. Xiao. (2005). Female engineers: New workforce in the hi-tech industry. Career Magazine. [Online]. 357. Available: http://www.media.career.com.tw/hot/hot_main.asp?CA_NO=357p128 $\& \mathrm{INO}=141$

[3] V. Oksman, "Virtual stables as girls own computer culture," in M. Consalvo and S. Paasonen, Eds., Women and Everyday Uses of the Internet, New York, NY: Peter Lang Publishing Inc, 2002, pp. 191-210.

[4] W. Lin, Children and the Internet: Rural Children's Internet Use in a Critical Aspect, Taipei: Showwe Information Co., Ltd, 2008.

[5] Y. Kafai, Minds in Play: Computer Game Design as a Context for Children's Learning, Hillsdale, NJ: Lawrence Erlbaum Associates, 1995.

[6] C. Ching, Y. Kafai, and S. Marshall, "Spaces for change: Gender and technology access in collaborative software design," Journal of Science Education and Technology, vol. 9, no. 9, pp. 67-78, 2000.

[7] D. Agosto, "Girls and gaming: A summary of the research with implications for practice," Teacher Librarian, vol. 31, no. 3, pp. 8-14, 2004.
[8] D. Malan and H. Leitner, "Scratch for budding computer scientists," in Proc. 38th SIGCSE Technical Symposium on Computer Science Education, New York, NY: ACM, 2007, pp. 223-227.

[9] J. Goode, R. Estrella, and J. Margolis, "Lost in translation: Gender and high school computer science," in J. M. Cohoon and W. Aspray, Eds., Women in Information Technology: Research on Under-representation, Cambridge, MA: MIT Press, 2006, pp. 89-114.

[10] Y. Kafai, "Gender differences in children's constructions of video games," in P. Greenfield and R. Cocking, Eds., Interacting With Video, Norwood, NJ: Ablex Publishing Corporation, 1996, pp. 39-66.

[11] Y. Kafai, "Video game designs by girls and boys: Variability and consistency of gender differences," in J. Cassell and H. Jenkins, Eds. From Barbie to Mortal Kombat: Gender and Computer Games, Cambridge, MA: MIT Press, 2000, pp. 90-114.

[12] L. Werner, S. Campe, and J. Denner, "Middle school girls + games programming = information technology fluency," in Proc. 6th conference on Information Technology Education (SIGITE'05), New York, NY: ACM, 2005, pp. 301-305.

[13] J. Giacquinta, J. Bauer, and J. Levin, Beyond Technology's Promise, Cambridge, England: Cambridge University Press, 1993.

[14] I. Utting, S. Cooper, M. Kölling, J. Maloney, and M. Resnick, "Alice, greenfoot and scratch - A discussion," ACM Transaction on Computing Education, vol. 10, no. 4, article 17, 2010.

[15] N. Rusk, M. Resnick, R. Berg, and M. Pezalla-Granlund, "New pathways into robotics: Strategies for broadening participation,' Journal of Science Education and Technology, vol. 17, no. 1, pp. 59-69, 2008.

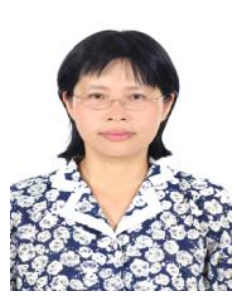

Hui-Mei Justina Hsu obtained her PH.D. from University of Illinois at Urbana-Champaign in 2006, majoring in curriculum and instruction. She is currently working as assistant professor at the department of learning and digital technology in Fo Guang University in Taiwan. Her research interests are technology integration, cultural aspect of educational computing and children programming. Dr. Hsu has been a member of IACSIT and IEEE since 2010.

She has attended various academic conferences in the field of educationa technology and serves as presenter as well as keynote speaker. 